\title{
Narrativas de passabilidade e a segurança para transitar: transmasculinidades e saúde
}

\author{
Rayssa Karla Dourado Porto ${ }^{1}$ \\ Marcos Aurélio da Silva ${ }^{2}$ \\ Sílvia Angela Gugelmin 3 \\ Universidade Federal de Mato Grosso
}

Resumo: O artigo parte das narrativas de homens trans sobre passabilidade para pensar os sentidos desta e a relação que eles tecem com a segurança para transitar nas ruas de cidades como Cuiabá, capital de Mato Grosso. Os sujeitos da pesquisa vivem o paradoxo de buscarem o reconhecimento de sua existência e visibilidade, ao mesmo tempo em que almejam a passabilidade para que desfrutem de uma invisibilidade que torne sua circulação pelos ambientes urbanos menos sujeita às violências físicas e simbólicas. Do ponto de vista deles, banheiros públicos e ruas possuem gramáticas excludentes àqueles que não correspondem à inteligibilidade binária de gênero. A discussão aponta para a necessidade de políticas públicas que garantam acesso a serviços de saúde ambulatoriais no Processo Transexualizador do SUS, em que as terapias hormonais são fundamentais para a conquista da passabilidade.

Palavras-chave: transmasculinidade; passabilidade; saúde LGBT; direito à cidade.

${ }^{1}$ Psicóloga graduada pela Universidade Federal de Mato Grosso (2014), com aperfeiçoamento clínico com ênfase em psicanálise pela UFMT (2015). Desde 2014, atua em consultório de psicologia clínica. Mestre em Saúde Coletiva pela UFMT (2020).

2 Professor adjunto do Instituto de Saúde Coletiva (ISC) e docente permanente do Programa de Pós-Graduação em Antropologia Social (PPGAS), na UFMT. Doutor em Antropologia Social pela Universidade Federal de Santa Catarina (UFSC, 2012), com pós-doutorado junto ao INCT Brasil Plural (UFSC, 2014). Pesquisador do Núcleo de Antropologia e Saberes Plurais (NAPlus/UFMT) e do Núcleo de Antropologia do Contemporâneo (Transes/INCT Brasil Plural).

3 Professor Associado do Departamento de Saúde Coletiva, do Instituto de Saúde Coletiva (ISC) da Universidade Federal de Mato Grosso. Graduada em Nutrição pela Universidade Federal do Paraná (1990), mestrado (1995) e doutorado (2001) em Saúde Pública pela Fundação Oswaldo Cruz. 


\title{
Passing narratives and the safety to transit: transmasculinities and health
}

\begin{abstract}
The article starts from the narratives of trans men about passing to think about the meanings of passability and the relationship they weave with the safety to transit on the streets of cities like Cuiabá, capital of Mato Grosso. The research subjects live the paradox of seeking recognition of their existence and visibility, at the same time they crave passability so that they enjoy an invisibility that makes their circulation through urban environments less subject to physical and symbolic violence. From their point of view, public restrooms and streets have grammars that exclude those that do not correspond to the binary intelligibility of gender. The discussion points to the need for public policies that guarantee access to outpatient health services in the Transsexualizing Process of the SUS, in which hormonal therapies are essential for the achievement of passability.
\end{abstract}

Keywords: transmasculinity; passing transgender; LGBT health; right to the city.

\section{Narrativas de pasabilidad y la seguridad para transitar: transmasculinidades y salud}

\begin{abstract}
Resumen: El artículo parte de las narrativas de hombres trans sobre la transitabilidad para reflexionar sobre los significados de la transitabilidad y la relación que tejen con la seguridad para transitar por las calles de ciudades como Cuiabá, capital de Mato Grosso. Los sujetos de investigación viven la paradoja de buscar el reconocimiento de su existencia y visibilidad, al mismo tiempo que ansían la transitabilidad para gozar de una invisibilidad que hace que su circulación por entornos urbanos sea menos sujeta a la violencia física y simbólica. Desde su punto de vista, los baños públicos y las calles tienen gramáticas que excluyen aquellas que no corresponden a la inteligibilidad binaria del género. La discusión apunta a la necesidad de políticas públicas que garanticen el acceso a los servicios de salud ambulatoria en el Proceso de Transexualización del SUS, en los que las terapias hormonales son fundamentales para el logro de la viabilidad.
\end{abstract}

Palabras clave: transmasculinidad; pasabilidad; Salud LGBT; derecho a la ciudad. 
$\mathrm{C}$ ircular pela cidade, frequentar banheiros públicos e desfrutar de uma certa invisibilidade - no sentido de não ser alvo de olhares e injúrias - pode parecer, mas não é normal no cotidiano de todos os sujeitos que compartilham os contextos urbanos, em cidades como Cuiabá, capital de Mato Grosso. A partir de narrativas de homens trans e de suas experiências de circulação em espaços públicos, o presente artigo tem o objetivo de pensar o conceito de passabilidade e sua complexidade. Além de representar um direito sobre sua identidade e seu corpo, a conquista da passabilidade para uma pessoa trans - ou seja, a produção de características corporais condizentes com sua identidade de gênero aponta para a segurança de transitar pela cidade e será aqui pensada como uma forma de produção de saúde, na medida em que implica em menos possibilidades de ser vítima de comportamentos LGBTfóbicos violentos e garante, entre outras coisas triviais, a possibilidade de utilizar banheiros públicos e não correr riscos de injúrias ou de adoecer por se privar disto.

Há, assim, um paradoxo entre invisibilidade (não ser alvo de agressões) e visibilidade (ser reconhecido como homem) que parecem marcar as narrativas apresentadas aqui. Quando pensamos no direito à cidade (LEFEBVRE, 1968), consideramos a premissa de que a urbanidade precisa estar aberta à diversidade de gramáticas e corporalidades que compõem contextos urbanos reais e não os idealizados por projetos e cosmologias que restringem a cidade a personagens e sujeitos legitimados por padrões de gênero, sexualidade, etnia e raça. Ocupar lugares intermediários em corporalidades ambíguas ou não inteligíveis torna a circulação de certos sujeitos arriscada e os faz construírem suas próprias gramáticas e práticas de espaço (DE CERTEAU, 1998). Por outro lado, ter legitimidade de circular pela cidade se produz, na maioria das vezes, numa invisibilidade, ou seja, a possibilidade de "passar batido", de não ser notado ou questionado, ser passável. Nesse sentido, não possuir uma cor de pele socialmente marcada ou performar gêneros inteligíveis - que não haja dúvida se alguém é homem ou mulher -, pode ser a diferença entre a segurança e a violência.

No caso das pessoas trans, atingir uma inteligibilidade de gênero, tem sido uma demanda importante em suas lutas por direito à saúde, o que coloca questões importantes para a saúde coletiva e para o Processo Transexualizador do Sistema Único de Saúde, em vigência no país (Portaria 1.707/2008 do Ministério da Saúde). Nesse sentido, as terapias hormonais são fundamentais para a produção visualmente inteligível de corpos generificados. Segundo a Nota Informativa 55/2019 do Ministério da Saúde, a terapia hormonal é um dos procedimentos ambulatoriais mais realizados pelo SUS, totalizando 2.203 intervenções em 2018. Rocon et al. (2018: 51) corroboram com o dado acima ao evidenciar que entre as mulheres transexuais e travestis, o implante de prótese mamária, a hormonioterapia e os cuidados integrais e multiprofissionais parecem destacar-se em relação às cirurgias de redesignação sexual.

\section{Passabilidade e pertencimento}

De acordo com a narrativa de André, 30 anos, estudante de pós-graduação, a construção dos caracteres sexuais no corpo transgênero, pode ou não ser um desejo, mas expressa que essa demanda surgiu de forma crucial na sua decisão para 
produção do corpo masculino. Rocon et al. (2018: 44) também pontuam que a transição pode ser realizada, no caso dos homens trans, para a obtenção de um corpo que represente o "pertencimento a uma perspectiva de gênero desejado" e assim possibilite felicidade, beleza, saúde, bem-estar físico, psíquico e social. Sobre essa questão da passabilidade, que também pode ser entendida como o desejo de transitar por entre as pessoas sem ser reconhecido como uma pessoa trans, Lima (2014) destaca que "não existe uma condição causal entre hormonização e performatividades transexuais". Para a autora, as transexualidades excedem a relação com os hormônios, assim não se encontram atreladas como uma expressão sine qua non:

a decisão de se hormonizar ou não, como vão se hormonizar, que fármacos utilizar, por quanto tempo, quantidades, efeitos, enfim faz parte de processos de agenciamentos marcados por uma multiplicidade de possibilidades que são negociadas a todo instante consigo mesmos/as e com ou outros. (LIMA, 2014: 114)

Lima (2014) assinala que não são todos os homens trans que expressam o desejo de intervenções como hormonioterapia. Na presente pesquisa, todos atribuíram importância fundamental aos hormônios e seu uso foi unânime entre os sujeitos participantes. As narrativas, que aqui serão apresentadas, desvelam a importância da continuidade e do acompanhamento adequados e ressaltam efeitos psicológicos e emocionais quando os entrevistados se veem diante da possibilidade de lidar com esses traços do corpo biológico feminino.

André relata que, por falta de conhecimento do endocrinologista, o ciclo receitado para uso da Deposteron (testosterona injetável) estava equivocado. Destaca que começou a sentir-se mal psicologicamente, evidenciando a sua disforia ao lembrar que ainda possui um sistema reprodutor feminino:

Então eu tava tendo cólica, eu tava tendo espinha de novo, eu tava morrendo de medo de voltar a ter sangramento. Enfim, foi um período que eu fiquei mega disfórico porque eu sentia. Quando eu comecei o tratamento e a menstruação parou, eu esqueci que eu tinha útero. Deixou de ser uma coisa que eu tinha consciência, e aí nesse momento foi muito difícil. Fiquei muito disfórico mesmo, porque eu senti que tinha ali uma coisa funcionando que eu não queria que estivesse ali. (André, julho de 2019)

Ávila (2014: 130), em sua pesquisa sobre transmasculinidades, descreve que "no que diz respeito às transformações corporais para tornar o corpo mais masculino, as cirurgias de retirada das mamas são o desejo de todos os homens trans que participaram da pesquisa". Assim como descrito pela autora, percebemos que dentre os entrevistados todos desejam a mastectomia, contudo para Severo José essa não é a prioridade, destacando como desejo primário a retirada do útero e ovários (histerectomia).

Os resultados aqui apresentados fazem parte da dissertação Da identificação da crise ao recomeço: Itinerário terapêutico de homens transgêneros na Baixada Cuiabana (MT), desenvolvida na área das ciências sociais e humanas em saúde do Instituto de Saúde Coletiva da UFMT, em que se buscou dialogar com a antropologia e a sociologia. O trabalho de campo ocorreu no período de junho a setembro de 2019 e foi realizada com sujeitos que buscam seu itinerário terapêutico na Baixada Cuiabana, uma das 16 regiões de saúde do estado de Mato Grosso (SCATENA et al., 2014), no Centro-Oeste do Brasil.

A coleta dos dados foi realizada por meio de entrevistas semiestruturadas, gravadas em áudio digital com a autorização dos participantes, orientadas por um roteiro que versava sobre a transexualidade, família, processo transexualizador, relacionamentos, saúde e rede de homens trans. Também se utilizou como re- 
curso um diário de campo onde foram anotados detalhes das entrevistas, percepções da entrevistadora e diálogos com os entrevistados em outros momentos para além da entrevista. Utilizou-se como critérios de inclusão: identificar-se como homem transgênero; ter mais de 18 anos; residir em um dos municípios da Baixada Cuiabana ou deslocar-se até algum desses munícipios para realizar os cuidados na área da saúde.

Após a participação da entrevista, os participantes receberam pseudônimos, conforme indicação do mesmo, com intuito de preservarmos sua identidade original. Tanto os nomes citados ou quaisquer outras referências que pudessem identificar os entrevistados foram modificadas e/ou suprimidas com intuito de garantirmos a confidencialidade 4 .

\title{
Passabilidade e os gêneros inteligíveis
}

O conceito de passabilidade foi referido por todos os sujeitos entrevistados. $\mathrm{O}$ termo passing transgender é descrito na literatura internacional para referirse a "uma capacidade pessoal de ser reconhecido/a como pertencente a um gênero que não era o assignado no sujeito ao nascer" (ALMEIDA, 2012: 519). Para o autor, a capacidade de passabilidade requer tanto as transformações físicas conquistadas por meio de hormônios e cirurgias, como também está ligada a performance e comportamentos que sejam culturalmente associados a tal gênero.

A narrativa a seguir dá conta de como o tema da passabilidade mexe com o cotidianos desses homens. César, 21 anos, estudante de graduação, indicou João, 19 anos, colega de faculdade, para participar da pesquisa e comentou sobre quando se conheceram:

\begin{abstract}
Foi no dia que eu fui fazer matrícula no semestre passado. A princípio eu achei que não era um menino trans, para você ver, né? Porque o preconceito vem de dentro da gente mesmo, porque ele tava na sala, e como ele não tinha feito nenhum tipo de alteração de característica, aí a professora chegou e falou assim: "aqui oh, seu parceiro, ele é menino trans também. (César, junho de 2019)
\end{abstract}

César pontua a questão relacionada ao preconceito construída com base nas características físicas do sujeito e nos estereótipos de "ser homem". Dentre todos os entrevistados, João é o único que manteve os cabelos longos: "Eu gosto do meu cabelo grande como ele é. Então eu não tenho problema com isso, tem muitos que cortam para parecer mais homem, ou alguma coisa do gênero".

O cabelo longo do João, associado ao fato deste não fazer uso do binder 5 , remete César ao não reconhecimento de João como um rapaz. Estamos diante de uma situação que demonstra como a passabilidade está intrinsecamente ligada às normas de corpos inteligíveis. A fala de César remete à sua expectativa em relação aos demais homens trans seguirem o mesmo padrão estético delineado pela sociedade cisheteronormativa. Lanz (2014: 129) assinala que a "passabilidade traduz o quanto uma pessoa transgênera se parece fisicamente, se veste, fala, gesticula e se comporta de acordo com os estereótipos do gênero oposto ao que lhe foi consignado ao nascer". A autora afirma que a passabilidade é considerada como algo fundamental para a população transgênera em dois aspectos: primeiramente, refere à segurança contra os ataques de violência transfóbica; o segundo

4 A pesquisa foi aprovada pelo Comitê de Ética em Pesquisa da Universidade Federal de Mato Grosso por meio do Certificado de apresentação para Apreciação Ética n. 05071318.3.000o.8124. Todos os entrevistados aceitaram participar voluntariamente e assinaram o Termo de Consentimento Livre e Esclarecido.

5 Tecido, atadura ou fita adesiva. É utilizado na região peitoral para comprimir os seios com intuito de deixá-los imperceptíveis sob as roupas. 
ponto tange à satisfação pessoal de ser publicamente reconhecido como alguém que a pessoa sempre sentiu que é.

Para entendermos a importância da passabilidade, precisamos entender o gênero e seus comportamentos como uma construção social. Butler (2003: 53) reflete sobre o fracasso quando se espera que gênero e sexo sejam coerentes com o eixo disjuntivo do feminino/masculino. Para a autora "as rupturas dessa coerência por meio do ressurgimento inopinado do recalcado revelam não só que a 'identidade' é construída, mas que a proibição que constrói a identidade é ineficaz”. Sobre a postura heteronormativa da sociedade, a autora afirma que são tentativas de instaurar o poder e a opressão masculina: "A univocidade do sexo, a coerência interna do gênero e a estrutura binária para o sexo e o gênero são sempre consideradas como ficções reguladoras que consolidam e naturalizam regimes de poder" (BUTLER, 2003: 59).

E quando não há passabilidade? Ou quando os gêneros não são inteligíveis? Todos os sujeitos participantes da pesquisar relataram incômodo com a presença dos seios, tanto que alguns já realizaram a mastectomia e outros utilizam o binder, exceto João. Durante a entrevista ele relatou ter cisto mamário, o que o impossibilita de usar binder e tops mais apertados:

\begin{abstract}
Eu percebo olhares estranhos, já percebi, já tive situações assim. Sempre que eu estou no banheiro masculino, reação do cara entrar e tipo: "será que eu estou banheiro masculino?" Só que aí eu olho e falo: "não, tá tudo bem, você está no banheiro certo, eu só sou um homem trans". Eu explico pra pessoa. Simplesmente lido com essa situação. Quando eu vou num lugar e o banheiro é unissex, eu vou tranquilo. Quando não tem, geralmente eu prefiro evitar. Porque eu sei que nem todo mundo vai ter cabeça aberta. Porque eu sei que nem todo mundo vai entender. (João, julho de 2019)
\end{abstract}

Esse relato demonstra a dificuldade de vivenciar sua identidade de gênero ao não performar conforme as regras estipuladas. Pontes e Silva (2017: 407) no trabalho acerca da cisnormatividade e passabilidade trazem a questão da performatividade de gênero. As autoras analisam que há uma disposição de um "conjunto de atos regulados e repetidos que asseguram uma imagem substancial de gênero no registro de uma matriz heterossexual e cisgênera”. Além disso, haveria práticas de produção e manutenção de uma determinada corporalidade, um "policiamento constante das fronteiras a fim de suprimir todo traço ambíguo que expusesse o trânsito de gênero frente às normas de inteligibilidade, comunicando os possíveis riscos da não inteligibilidade naquele contexto" (PONTES e SILVA, 2017: 408).

\title{
Banheiros públicos, a gramática das ruas e a segurança para transitar
}

A fala de João destaca os desafios que as pessoas trans enfrentam diariamente, sendo o uso do banheiro um dos principais. Enquanto João ainda passa por situações constrangedoras, Acácio, gastrônomo de 42 anos, relata que utilizar o banheiro se tornou um ponto que validou sua passabilidade. Conta que, quando estava acompanhado da sua filha, utilizava o feminino. Mas em algum momento precisou escolher:

O banheiro foi decisivo, quando assim, eu percebi que eu não poderia mais usar o banheiro feminino, eu já comecei a sentir isso! Entendeu? E sempre me confundiram com homem... quando eu ia nos lugares, as pessoas olhavam e falavam 'pô, é um cara', né? E aí olhavam pros seios, pediam desculpa, não sei o que... (Acácio, agosto de 2019) 
Assim como relatado por Acácio, concomitante ao assunto da passabilidade emerge a questão do uso de banheiro em locais públicos. Por vezes, os sujeitos entrevistados descreveram se sentir não apenas desconfortáveis, mas na iminência de perigo e ataques transfóbicos. Cruz (2011: 81) afirma que o modo de organização dos banheiros não é algo tão "inocente" ou "natural". Para a autora, a racionalidade que vigora nestes espaços está a serviço de reafirmar a heteronormatividade e a perspectiva binária do gênero: "Justo o espaço do banheiro, tão dedicado as funções 'naturais', disfarçadamente (?) precisou ser esquadrinhado para controle dos corpos, das sexualidades e dos gêneros!" César conta que já passou por uma situação na qual mesmo sem ter passabilidade para frequentar o banheiro masculino, também não havia a leitura de um corpo feminino para frequentar o outro banheiro:

\begin{abstract}
Porque no início, eu não tinha mudado fisicamente, então o meu rosto parecia mais feminino. E aí aconteceu de eu não poder entrar no banheiro masculino porque os meninos olhavam feio, mas na época eu frequentava o $R U$ [restaurante universitário], então o banheiro é muito maior, tinha muito mais gente, e aí eu tinha que usar banheiro feminino. E lá no banheiro feminino as pessoas acharam que eu era um menino e queriam me expulsar. Ou seja, eu não podia usar nenhum dos dois, entendeu? E já aconteceu uma vez, de eu brigar com uma a senhora do feminino porque ela falou que isso era um abuso, porque eu era um menino que estava no banheiro feminino. E de certa maneira eu me senti bem (risos). Porque ela achou que eu era um menino, e ela estava certa, né? (César, junho de 2019)
\end{abstract}

Após essa situação, César relata que começou a usar o banheiro masculino independente da sua passabilidade, se posicionando enquanto homem trans perante a sociedade, assumindo assim os riscos de sua escolha:

A partir do momento que eu falei eu sou o César, eu sou homem trans, eu passei não usar mais o banheiro feminino. Estando com binder, ou não, estando com músculos, ou não, eu comecei a usar o banheiro masculino. Dei a cara a tapa, entendeu? (César, junho de 2019)

Em um contexto no qual entendemos que há normas e que se espera um padrão de comportamento nas sociedades cisheteronormativa, a quebra desses padrões pode lançar luz nessas pessoas de forma a expô-las, deixando-as vulneráveis. Assim, a passabilidade emerge, sobretudo, como questão de segurança para transitar na sociedade. André traduz a angústia de ser lido enquanto um corpo não inteligível:

E quando a demanda [pela transição] veio latente mesmo eu comecei a me sentir muito vulnerável, mas no sentido de muito visível. Eu sempre uso uma metáfora, e eu acho que ela é muito boa, que é a de um filhote de jacaré albino no Pantanal. Ele não dura dois minutos porque todo mundo o vê, é um negócio que brilha no sol, ele nasce e o passarinho já vem e come ele. Então eu me sentia muito assim e ainda me sinto. Porque é aquela história: hormônio não faz milagre. Então a minha leitura em muitos momentos ainda é de uma pessoa trans, essa que é grande questão. Eu acho que as pessoas não conseguem ler me generificando ainda. [...] E é isso. Quando as pessoas, elas não conseguem ler a gente, fica muito difícil elas considerarem a gente humano e aí tem umas coisas que são muito julgativas, né? (André, julho de 2019)

Os indivíduos de gêneros não-inteligíveis se encontram em outra esfera da vida social, sendo essa uma zona invisível e inabitável (ÁVILA, 2014) e a falta da leitura social binária sob os corpos, os situam nesse espaço hostil. Consideramos assim que as violências transfóbicas ocorrem pelo não reconhecimento do gênero binário, ignorando-se que anterior a um sistema de sexo e gênero existem pessoas, deixando-as à mercê dos diversos tipos de violência.

Todos entrevistados relataram que quando não há segurança ou privacidade para utilizar o banheiro masculino (por vezes este conta somente com mictórios, 
ou ainda há relatos da cabine onde fica o vaso sanitário estar trancada/sem porta), diante da impossibilidade de usar o banheiro feminino, optavam por não satisfazer as necessidades biológicas, isto é, não vão ao banheiro mesmo quando precisam.

Tenho medo de identificarem ali. Eu não uso o packer, então eu sempre vou aonde tem cabine. Teve uma vez que eu fui revistado no aeroporto de Salvador, eu tenho certeza de que foi porque tinha um segurança no banheiro e eu fui usar o banheiro e eu acho que ele viu que eu ao invés de ficar de frente eu fiquei de costas. (André, julho de 2019)

De acordo com Preciado (2019: 4), os banheiros não servem simplesmente para evacuar, mas fazer nossas necessidades de gênero: "Não vamos urinar, mas reafirmar os códigos de masculinidade e feminilidade no espaço público". O autor faz uma análise acerca da arquitetura dos espaços para demonstrar como estes funcionam como tecnologias de gêneros, regulando o que mostrar e o que esconder nas performances fisiológicas. Dessa maneira, o mictório não é apenas funcional para as excreções, mas também um instrumento que participa da produção da masculinidade no espaço público.

Preciado (2019: 3) ainda pontua que, desde o início do século XX, foi estabelecida como que uma lei arquitetônica de padrão na construção dos banheiros masculinos, instituindo a separação de funções entre mictório e o vaso sanitário: "a produção efetiva da masculinidade heterossexual depende da separação imperativa de genitalidade e analidade”. A fala de André demonstra que a maneira como ele utilizou o vaso sanitário possa ter servido para que o segurança desconfiasse de sua atitude e o decidisse revistá-lo. Léo, 23 anos, nutricionista e professor, conta sobre sua primeira experiência no banheiro masculino:

(...) eu consigo ficar muito tempo sem ir no banheiro e isso não é bom. Eu criei esse mecanismo, eu bebo e não vou ao banheiro, eu consigo esperar às vezes ir pra casa depois de uma noite inteira de farra e bebedeira pra ir no banheiro em casa, e aí eu comecei a perceber que isso não tava certo. Eu tento me forçar a ir em lugares que tem banheiro. Eu fui a um bar, antes de eu fazer a cirurgia, fui numa boate e eu me senti preparado para entrar no banheiro masculino e aí eu fui, suei, mas depois que eu fui a primeira vez nunca mais fui no banheiro feminino, foi bom. A sensação é boa. A primeira vez você acha que tá todo mundo te olhando, tipo: "ah, você é trans". Mas depois passa essa mania de perseguição que a gente tem no início. (Léo, julho de 2019)

Nesse relato podemos perceber o desconforto e o medo de utilizar o banheiro masculino. Relatos semelhantes foram realizados por André, que conta que "muitos meninos, vários amigos não vão ao banheiro de jeito nenhum”. Severo José, estudante universitário de 22 anos, menciona que "antes, eu nem entrava em banheiro. Em balada, por exemplo, em barzinho que eu vou, não entro no banheiro, e aí acabou!". Gerson, de 28 anos, relata sentir-se privilegiado em ser músico e trabalhar em ambientes mais descontraídos:

\footnotetext{
Mais um privilégio! Como os bares que eu frequento são os bares que eu toco, eu poderia ir no banheiro de funcionário, entendeu? Eu não preciso passar por fila, não preciso ir nos banheiros! Mas os meus amigos sofrem! Só que teve uma época que eu não mijava, dependendo do lugar que eu fosse, entendeu? Eu não mijava... Eu chegava com a minha bexiga estourando em casa e dava um jeito de mijar num... sei lá sabe, atrás de um carro, para não ter que passar pelo constrangimento. É difícil, o lance do banheiro, é pesado! E só um banheiro, só... um lugar pra mijar. (Gerson, agosto de 2019)
}

Mesmo não sendo relatado ocorrências de agressões, os entrevistados nos contaram que evitam a utilização dos banheiros por medo e receio da iminência de um ataque violento. Contudo, precisamos refletir sobre as consequências de 
segurar a urina por tanto tempo, visto que esse hábito pode trazer consequências como infecções, incontinência urinária e cálculo renal ${ }^{6}$. A falta de segurança em utilizar os sanitários tem também implicações sociais, pois o desconforto em utilizar qualquer banheiro público traz restrições a locais que são possíveis de serem frequentados. Ou seja, esses sujeitos não possuem pleno direito de ir e vir.

Outra forma de pensar passibilidade é descrita por Duque (2013) que pauta o conceito com o significado de "passar por" enquanto regime de visibilidade/ conhecimento. No entanto, essa perspectiva é contestada por dois entrevistados:

\begin{abstract}
(...) então eu me sinto vulnerável nesse sentido. Muito dessa questão da passabilidade eu vejo as pessoas associarem a "passar por". Eu não vejo que seja "passar por", para mim eu não quero passar por ninguém. Eu não quero passar por nada. Eu quero poder transitar, passar por entre as pessoas, pelos lugares, sem ter essas incidências sobre mim, então eu acho que tem muito mais a ver com isso. (André, julho de 2019)

Tem a passabilidade que nem todo mundo tem, que é essa coisa de você chegar num lugar, as pessoas não sabem que eu sou trans, só quem me conhece, de antes! E mesmo assim, essas pessoas já até cansaram. (Gerson, agosto de 2019)
\end{abstract}

André deseja se sentir como qualquer outra pessoa sem ter sobre si a incidência da dúvida e o medo da violência sobre seu corpo se frequentar determinados lugares. Neste aspecto compreendemos a importância atribuída pelos sujeitos a mastectomia e uso dos hormônios para aquisição dos caracteres sexuais secundários. Não se trata somente da satisfação pessoal com o corpo, mas de sentir-se seguro para transitar pela cidade. André complementa:

Cara, quando eu uso o binder eu me sinto mais vulnerável ainda, porque as pessoas olham e não é uma questão assim, eu me sinto invadido porque é um saco as pessoas olharem. Eu me sinto vulnerável em termos de segurança. (André, julho de 2019)

De acordo com Pontes e Silva (2017: 404), ao estabelecer como objetivo último da transição a possibilidade de 'passar por cis', a transição de gênero restringe a passabilidade como "horizonte normativo [que] acaba por definir e aplicar valores aos corpos e, por conseguinte, aos próprios sujeitos, explicitando relações de hierarquia". Mais ainda, as autoras enfatizam que "perder-se na multidão" pode ser compreendido como um tipo de reconhecimento de um corpo trans que é lido como não-trans ou cis, o que nos faz pensar que a subversão da leitura social permite escapar de determinadas violências dirigidas aos corpos vistos como não inteligíveis pelas categorias homem/mulher no registro cisgênero.

\begin{abstract}
Hoje em dia está mais tranquilo, mas ao mesmo tempo não. Porque antes eu conseguia acessar o banheiro feminino quando eu julgava que era mais seguro. Por exemplo, rodoviária, às vezes eu vou daqui para São Paulo de ônibus, sinceramente eu não ia me colocar em uma situação de risco à toa né? Porque eu tô lá numa biboca, sem ninguém, viajando sozinho, então durante muitos anos eu nesses momentos usava o banheiro feminino sim, nem pensava duas vezes. Privilégio? Acho que é estratégia de sobrevivência na verdade. E hoje já não rola mais e eu não sinto mais à vontade porque eu sei que a leitura já é outra. (André, julho de 2019)
\end{abstract}

Ao pensar nas coletividades e socialidades pautadas no binarismo homem/ mulher, Lanz (2014: 135), pontua que a passabilidade serve para ratificar esse sistema. A autora pondera que, em vez de constituir elementos de luta pelo direito constitucional de livre expressão, direito que contempla a expressão da identidade de gênero com a qual a pessoa mais se identifica, a passabilidade torna as fronteiras de gênero ainda mais sólidas. Almeida (2012: 519) reflete acerca do desejo de sumir na multidão, o 'direito à indiferença'. Compara que em relação as

6 Mais informações em https://drauziovarella.uol.com.br/sexualidade/preconceito-e-falta-de-acesso-a-banheiros-aumentam-o-risco-de-infeccao-urinaria-em-pessoas-trans/ 
mulheres trans, os homens trans tem mais facilidades na passabilidade possibilitando práticas de camuflagem social que favorecem o conforto e o acesso individual a direitos. $\mathrm{O}$ autor analisa que, politicamente, a passabilidade dos homens trans, traz consigo um esvaziamento político no ativismo e na militância das causas da população trans.

\section{Passabilidade, serviços de saúde e produção corporal}

Outro tópico mencionado por Gerson, ao contar sobre a sua vivência, é o seu privilégio de poder utilizar o banheiro destinado aos funcionários, mesmo não estando a trabalho, situando a dificuldade encontrada pelos outros homens em situações equivalentes. Em alguns momentos da entrevista, Gerson falava sobre a importância da presente pesquisa, mas essa fala sempre veio acompanhada de um, "mas você precisa ouvir a história das pessoas de verdade". Ao ser questionado sobre o que isso significava, quem deveria ser entrevistado, Gerson responde que são as pessoas que não são as privilegiadas: "realmente o cotidiano de alguém que vai trabalhar de manhã cedo e volta à noite, tem que ir no médico, tem que pagar as contas, não consegue dinheiro, sabe?"

Destaca assim que se sente em uma situação que não reflete a realidade da maioria dos homens trans, pois considera um privilégio a sua profissão ser em uma área menos conservadora. Gerson relatou trabalhar muito para poder pagar pela mastectomia. Dos entrevistados aqui, foi o único que abandonou os estudos, não completando o ensino médio, mas ressignificou sua história por meio da sua transição de gênero:

\footnotetext{
Pra você ter uma ideia, na minha cabeça eu peguei a história da minha vida, até o momento que eu não tinha crescido seios, e aí eu recortei na minha mente assim, e colei com essa nova fase, ou seja, sempre foi assim, entendeu? Nunca houve a fase de ter crescido, stress, a raiva, pra mim, eu pulei... eu não sei como que isso funciona, mas funciona... funciona! (Gerson, agosto 2019)
}

Talvez seja possível dizer que todos os entrevistados desejam a transição de gênero, para fazer esse recorte que Gerson narra e assim terem a possibilidade de recomeçar suas vidas superando o momento de crise. O itinerário terapêutico que os sujeitos percorrem em busca do processo transexualizador é diverso, mas está vinculado à passabilidade do gênero binário, construído como homem-mulher. $\mathrm{O}$ que verificamos é que a busca pela inteligibilidade e passabilidade limita a vivência desses sujeitos ao torná-los inseguros e vulneráveis ao assumir uma posição não binária. Isso pode ser importante para pensarmos sobre a necessidade de desconstruir categorias binárias, que levam a rotular e engessar as pessoas.

As consultas, exames e aplicações hormonais serão perenes. Então, o itinerário terapêutico é perpassado de conflitos e angústias sobre as intervenções que desejam realizar. Todos os sujeitos que participaram desse estudo fazem uso de hormônios, apontando este como crucial para corporificação das suas identidades de gêneros sendo um ponto unânime entre os entrevistados.

Os entrevistados demostram interesse sobretudo em intervir cirurgicamente para retirada as mamas e do aparelho reprodutor feminino (histerectomia). A mastectomia é descrita como um desejo entre todos os entrevistados, sendo que dois sujeitos já realizaram tal procedimento. Assim como descrito na literatura, a importância da mastectomia relaciona-se com o conceito de passabilidade, visto que os seios são apontados como um marcador de gênero. A realização da histe- 
rectomia é descrita sempre acompanhada do termo necessidade, pois o uso prolongado da testosterona causa danos aos órgãos femininos e a não retirada desses pode desencadear problemas como cólicas e câncer. Apenas um sujeito atribuiu principal importância para a retirada do útero. Sobre as cirurgias de transgenitalização, como a faloplastia (constituição cirúrgica de um pênis) e a metoidoplastia (retificação e alongamento do clitóris, com estímulo hormonal), apenas um homem trans pontuou sobre o interesse em realizá-las.

\section{Considerações finais}

Mais do que um direito sobre sua identidade e corpo, as vozes dos homens trans e as narrativas de passabilidade que tiveram lugar neste trabalho apontam a questão da segurança para transitar, ou seja, o direito à cidade como um horizonte de vida baseado num corpo inteligivelmente generificado. Um sujeito pontuou que, após a entrevista, começou a se questionar sobre o desejo da mastectomia, se seu desejo estaria pautado em si mesmo ou na necessidade de adequar o seu corpo à expectativa da sociedade. Assim, é interessante pensar como a legitimidade dos corpos se produz em cima de um binarismo supostamente baseado numa natureza biológica, o que nos leva ao conceito de biolegitimidade

Em diálogo com Didier Fassin, Sônia W. Maluf (2018: 15) tem pensado no conceito de biolegitimidade como um "dispositivo de produção de direitos, ou de reconhecimento e de acesso a serviços e atendimento por parte do Estado, e também como meio de reinvindicação e conquista de direitos". Trata-se de um deslocamento das demandas por direitos sociais e econômicos para o "direito à vida", ou seja, os parâmetros para as demandas sociais "esvaziam em grande parte seus sentidos políticos”. O que impacta os próprios movimentos sociais e não apenas o Estado, em especial os sujeitos trans, como aponta Maluf, com uma "centralidade na intervenção biomédica ou medicamentosa através de hormônios e cirurgias".

A passabilidade, como apontou Almeida (2012), muitas vezes implica um esvaziamento do político da militância trans, o que pode ser entendido nesse deslocamento da ideia de "direito social" para a ideia de "direito à vida", como nos mostram as reflexões sobre biolegitimidade de Maluf e Fassin (2004; 2006). Talvez isto também nos ajude a entender o próprio movimento LGBTI, em suas demandas políticas recentes que parecem ter de fundo tal ideia de direito à vida, na medida em que as sexualidades são defendidas quase como naturais (não necessariamente biológicas), mas bastante afastadas de uma construção sociocultural - o que no senso comum parece remeter à ideia de escolha7.

Recebido em 31 de março de 2021.

Aprovado em 10 de abril de 2021.

7 Como na Parada do Orgulho LGBT de São Paulo, em 2015, cujo tema era "Eu nasci assim, eu cresci assim, vou ser sempre 


\section{Referências}

ALMEIDA, Guilherme. 'Homens trans': novos matizes na Aquarela das masculinidades? Estudos Feministas, 20(2): 513-23, 2012.

ÁVILA, Simone. FTM, transhomem, homem trans, trans, homem: A emergência de transmasculinidades no Brasil contemporâneo. Tese de Doutorado, Programa de Pós-Graduação Interdisciplinar em Ciências Humanas, UFSC, 2014.

BRASIL. Portaria 1.707, de 18 de agosto de 2008. Institui, no âmbito do Sistema Único de Saúde (SUS), o Processo Transexualizador, a ser implantado nas unidades federadas, respeitadas as competências das três esferas de gestão. Brasília: Ministério da Saúde, 2018.

BUTLER, Judith. Problemas de gênero: feminismo e subversão da identidade. Belo Horizonte: Civilização Brasileira, 2003.

CRUZ, F. L. Banheiros, travestis, relações de gênero e diferenças no cotidiano da escola. Psicologia Política, 11 (21): 73-90, 2011.

DE CERTEAU, M. A Invenção do Cotidiano. 1. artes de fazer. $3^{\text {a }}$ ed. Petrópolis: Vozes, 1998.

DOURADO PORTO, Rayssa Karla. Da identificação da crise ao recomeço: Itinerário terapêutico de homens transgêneros da Baixada Cuiabana/MT. Dissertação de Mestrado, Programa de Pós-Graduação em Saúde Coletiva, Universidade Federal de Mato Grosso, 2020.

FASSIN, D. Entre las políticas de lo viviente y las políticas de la vida: Hacia una antropología de la salud. Revista Colombiana de Antropología, 40: 283-318, 2004.

FASSIN, Didier. La biopolitique n'est pas une politique de la vie. Sociologie et sociétés, 38 (2): 35-48, 2006.

LANZ, Letícia. O corpo da roupa: A pessoa transgênera entre a transgressão $e$ a conformidade com as normas de género. Dissertação de Mestrado, Programa de Pós-Graduação em Sociologia, Universidade Federal do Paraná, 2014.

LEFEBVRE, Henri. O direito à cidade. São Paulo: Centauro, [1968] 2001.

LIMA, Fátima. Corpos, Gêneros, Sexualidades: Políticas de Subjetivação. Porto Alegre: Rede Unida, 2014.

MALUF, Sônia W. "Biolegitimidade, direito e políticas sociais: novos regimes biopolíticos no campo da saúde mental no Brasil”. In: MALUF, S. W.; SILVA, E. Q. (orgs.). Estado, políticas e agenciamentos sociais em saúde: etnografias comparadas. Florianópolis: EdUFSC, 2018. pp. 15-44.

PONTES, Júlia C.; SILVA, Cristiane G. Cisnormatividade e passabilidade: deslocamentos e diferenças nas narrativas de pessoas trans. Periódicus, 1 (8): 396-417, 2017.

PRECIADO, Paul B. Lixo e Gênero, Mijar/Cagar, Masculino/Feminino. eRevista Performatus, 7 (20): 1-5, 2019. M. O que esperam pessoas trans do Sistema Único de Saúde? Interface - Comunicação saúde educação, 22 (64): 43-5, 2018. 